\title{
PERFIL TENSIVO E ESTRATÉGIAS DE CONSTRUÇÃO DA TENSÃO \\ EM O BARRIL DE AMONTILLADO, DE EDGAR ALLAN POE
}

TENSIVE PROFILE AND STRATEGIES FOR

BUILDING TENSION IN THE CASK OF

AMONTILLADO, BY EDGAR ALLAN POE

Dayane Celestino de Almeida' 
RESUMO: A leitura de textos de terror/horror costuma fazer emergir comentários em torno da "tensão" que deles emana. Mas o que é a esta tensão em um texto? Ou melhor: por meio de que mecanismos, se constrói a tensão dentro de uma obra? É possível reconhecer um percurso, um "esqueleto" tensivo, com momentos de atenuação ou exacerbação da tensão, por trás de uma história? Este artigo procura responder a essas perguntas a partir da análise do conto "O barril de Amontillado", de Edgar Allan Poe, tomando como base teórico-metodológica a semiótica tensiva.

PALAVRAS-CHAVE: Contos de horror; Tensão; Semiótica tensiva; Semiótica da literatura.

ABSTRACT: The reading of terror/horror tends to bring out comments about the "tension" that emanates from these texts. But what is tension in a text? Or rather: how is tension built within a work? Is it possible to recognize a tensive trajectory? A tensive structure showing moments of attenuation or exacerbation of tension? This article seeks to answer these questions from the analysis of the short story "The cask of Amontillado", by Edgar Allan Poe, using the tensive semiotics as a theoretical and methodological basis.

KEYWORDS: Horror short stories; Tension; Tensive semiotics; Semiotics of literature. 


\section{CONSIDERAÇÕES INICIAIS}

A leitura de textos de terror/horror costuma fazer emergir comentários em torno da "tensão" que deles emana. "É um texto muito tenso" ou "aquela passagem foi tensa demais" são exemplos de falas nesse sentido. Mas o que é esta tensão em um texto? Ou melhor: como, por meio de que mecanismos, se constrói a tensão dentro de uma obra? E, por último: é possível reconhecer um percurso, um "esqueleto" tensivo, com momentos de atenuação ou exacerbação da tensão, por trás de um texto? Este artigo procura responder a essas perguntas a partir da análise do conto "O barril de Amontillado", de Edgar Allan $\mathrm{Poe}^{2}$. Tomamos como norte teórico-metodológico o quadro de reflexões do linguista e semioticista Claude Zilberberg (2006a, 2006b), que se debruçou sobre a questão da tensividade na construção do sentido dos textos e discursos.

A pertinência de tal abordagem teórica da literatura de horror se observa, de um lado, pela afinidade desses campos em torno da noção de afeto; a semiótica tensiva de Zilberberg é uma teoria da primazia do afeto na construção do sentido. Ela postula que há uma prioridade do sensível sobre o inteligível e se assenta na importância da percepção; o horror, por sua vez, é definido enquanto gênero pela sua "capacidade intencional de suscitar um certo sentimento" ${ }^{3}$ (CARROLL, 1990, p.14, grifo do autor, tradução nossa $)^{4}$ - no caso, o próprio sentimento de horror ou de medo. De outro lado, nos parece evidente que picos (ou “acentos", saliências) de tensão perpassam as obras de horror e, assim, justifica-se o exame da construção da emergência desses acentos por um quadro teórico que se debruça sobre os seus mecanismos.

A partir da análise que segue, procuramos demonstrar que não só há aumentos gradativos da tensão ao longo do conto, mas também que o texto é, em sua base,

2 Para esta análise, empregamos a tradução de José Paulo Paes, publicada pela Companhia das Letras (ver POE, 2017), com breves cotejos com a versão em inglês que está disponível em <https:// www.ibiblio.org/ebooks/Poe/Amontillado.pdf>.

3 No original "affect", que poderia ser também traduzido por "afeto", mas cremos que, em Português, "sentimento" seja um uso mais frequente.

4 Texto original: "novels are denominated horrific in respect of their intended capacity to raise a certain affect" (CARROLL, 1990, p. 14). 
tenso $^{5}$. O que ocorre em "O barril de Amontillado" não é uma passagem de um estado de total relaxamento para momentos de tensão, mas sim, o estabelecimento de uma tensão "primeira", de base, que perpassa todo o texto e que é exacerbada em momentos específicos. Procuramos, ainda, apresentar os mecanismos linguístico-discursivos da construção da tensão nos dois casos, isto é, as estratégias que estão por trás de seu afloramento. Para levantar esses mecanismos linguístico-discursivos, nossa base é o quadro mais geral da teoria semiótica francesa (GREIMAS \& COURTÉS, 1979).

Compreender as estratégias de construção da tensão em um conto de horror pode ser útil, futuramente, em algumas frentes, a saber: a) na melhor delimitação ou caracterização do horror enquanto gênero; e b) na composição de uma "caixa de ferramentas" a ser disponibilizada aos escritores de horror, que podem partir de tais ferramentas para arquitetar suas obras visando este ou aquele grau de tensão e impacto que ajudarão a compor o desejado "sentimento de horror" ou "efeito de horror", requerido pelo gênero, segundo a definição supracitada de Carroll (1990).

Alguns conceitos da semiótica e da sua vertente tensiva ${ }^{6}$ relevantes para este artigo serão apresentados na próxima seção, em conjunto com a análise do conto. Sobre este, cabem, ainda nesta breve introdução, algumas palavras. Trata-se de uma publicação de 1846, com a história de um homem - Montresor, o narrador - que executa uma vingança macabra e, ao que parece, desproporcional, após uma série de injúrias e insultos (que o leitor nunca chega a saber quais foram, exatamente) desferidos por um conhecido - Fortunato. Apresentamos detalhes do texto e seu desfecho ao longo da análise.

Esperamos demonstrar a aplicabilidade dos conceitos e reflexões da semiótica sobre a construção da tensão, trazendo, ainda que modestamente, algumas luzes aos estudos que procuram entender como o sentido se constrói em textos literários de horror.

5 Usaremos intercambiavelmente os termos "tenso", "intenso" e "tônico" e também "tensão" e "intensidade" no intuito de tornar a apresentação das ideias mais fluidas aos não iniciados em semiótica tensiva, embora saibamos que estes termos podem ter conotações diferentes em alguns pontos da teoria.

6 Iniciada por Zilberberg, mas que continua sendo desenvolvida por outros pesquisadores e também empregada em diversos tipos de análise, sobretudo no Brasil (e.g. TATIT, 2001 e 2019). 


\section{CONFIGURAÇÕES TENSIVAS DE O BARRIL DE AMONTILLADO}

A semiótica francesa é uma teoria e também um método de análise dos textos e discursos. Ela visa entender como o sentido é construído e apreendido nos diferentes tipos de textos ${ }^{7}$, inclusive os literários ${ }^{8}$. De modo geral, pode-se dizer que a semiótica procura compreender como um texto opera para dizer o que diz (BARROS, 2003a), isto é, quais estratégias enunciativas e quais mecanismos linguístico-discursivos estão por trás de sua estruturação. Tendo sido fundada em meados do século XX (GREIMAS, 1966, 1970; GREIMAS \& COURTÉS, 1979), a semiótica francesa conta com um grande arcabouço teórico e metodológico e também com algumas visadas diferentes sobre a questão do sentido e da significação. Essas várias vertentes se complementam e focalizam distintos aspectos da construção do sentido.

Dentre essas visadas, está a chamada semiótica tensiva (ZILBERBERG, 2006a e 2006b), que se ocupa, grosso modo, do entendimento da modulação entre relaxamento e tensão, entre continuidades e descontinuidades e do aspecto sensível de uma obra. Muitos são os conceitos englobados por este quadro teórico e, obviamente, foge do escopo deste artigo abordá-los todos ${ }^{9}$. Dessa forma, vamos lançar mão de um ou outro conceito que se mostrar relevante para a análise que propomos, partindo de uma metodologia centrada no objeto, isto é, que parte do texto e busca na teoria as ferramentas para seu entendimento.

O primeiro desses conceitos é a noção de "acento". A semiótica tensiva propõe

7 “Texto" é aqui entendido como a junção de um plano de expressão e um plano de conteúdo, em qualquer linguagem, seja ela verbal, não verbal ou sincrética. As noções de plano da expressão e plano de conteúdo foram primeiramente propostas pelo linguista dinamarquês Louis Hjelmslev (2005 [1943]), num desenvolvimento da dicotomia "significante e significado", de Saussure (2002 [1916]).

8 De fato, diversas das primeiras análises de Greimas se debruçaram sobre textos literários e há, ainda hoje, vários pesquisadores, inclusive no Brasil, analisando literatura a partir deste ponto de vista. Para maior entendimento sobre uma semiótica da literatura, ver Bertrand (2003).

9 Para uma visão geral da semiótica tensiva, ver Zilberberg (2006). Para análises semióticas envolvendo a teoria, ver Tatit (2001). 
a existência de "acentos" de conteúdo, análogos aos acentos prosódicos: do mesmo modo que uma palavra ou frase se constrói sonoramente pela alternância entre sílabas fracas e fortes (as fortes sendo as "acentuadas"), os textos teriam também pontos fracos ou pontos fortes ("átonos" ou "tônicos"), em termos do conteúdo. Grosso modo, algo "acentuado" é algo "enfatizado".

Mas o que cria essa acentuação do conteúdo? Tudo aquilo que constitui uma quebra de expectativa, uma ruptura, uma descontinuidade. Zilberberg (2006b) observa que os textos podem ser da ordem da implicação (se algo é X, então Y ocorre) ou da ordem da concessão (apesar de algo ser X, Y ocorre). A tensão aflora sobretudo diante das concessões, do inesperado.

Os inesperados, os momentos concessivos, podem ser encontrados em diferentes níveis do texto. Podem estar no modo como a narrativa é estruturalmente organizada ou no modo como aparecem os temas e os revestimentos semânticos desses temas; podem, ainda, estar inscritos dentro do enunciado ou, ao contrário, advirem de relações entre enunciador e enunciatário-leitor (no nível da enunciação, instância produtora do enunciado); podem também advir de uma articulação de valores fundamentais da obra que difira do que se é esperado em dado momento histórico; e assim por diante.

O que a semiótica tensiva chama de "tensividade" é uma junção entre duas dimensões que estão sempre presentes em quaisquer grandezas textuais-discursivas (ZILBERBERG, 2006a). A primeira dessas dimensões é chamada de "intensidade" e ela tem a ver com a tonicidade e o andamento dos textos. Conteúdos mais acelerados, isto é, que adentram mais rapidamente e/ou abruptamente o campo de presença dos sujeitos - que podem ser os sujeitos do enunciado (as personagens), ou da enunciação (o leitor) - são mais tônicos, fortes, criadores, portanto, de tensão e, algumas vezes, de impacto. A segunda dimensão é chamada "extensidade" e nela se desdobram o espaço e o tempo que, a depender de sua concentração ou difusão, afetam o grau de tensão e de impacto.

Para esclarecer esses princípios teóricos, valhamo-nos de um exemplo envolvendo a expressão idiomática "o gato subiu no telhado", empregada por vezes para introduzir uma notícia ruim de modo paulatino. Digamos que a notícia a ser dada 
seja "a morte do gato". Se o gato não estava doente, este conteúdo, além de provocar comoção, é inesperado, por isso forte; e se a notícia for dada "de uma vez", dizemos que ela é impactante, porque tira de repente o sujeito de sua "zona de conforto" ("tira-lhe o chão"). Contudo, tal impacto é atenuado se a mesma notícia de morte for passada ao sujeito de maneira difusa, no decorrer de três momentos, assim: "O gato subiu no telhado; o gato caiu do telhado; o gato morreu". O espalhamento da notícia no tempo atenua o impacto que era, ao contrário, extremo, quando essa notícia era concentrada em um único momento. Então, extensidade (tempo e espaço) e intensidade (força e andamento) são dimensões correlacionadas. Ademais, do tipo e do grau de correlação dependem os efeitos de sentido de tensão ou impacto nos textos. Novamente, reforçamos que rupturas, descontinuidades, causam os momentos fortes, tensos, acentuados (até mesmo porque são, na maior parte das vezes, abruptas, inesperadas; concentradas e não difusas no tempo).

Como já mencionado na Introdução, na análise aqui apresentada, procuramos mostrar que mecanismos linguístico-discursivos atuam no conto para construir: a) uma tensão em sua base; e b) a exacerbação desta tensão nas saliências, acentos, momentos tônicos.

\section{TENSÃO COMO BASE DO TEXTO}

Um texto pode partir de um estado de relaxamento, de atonia, mas em "O barril de Amontillado" já parte da tensão, da tonicidade, desde sua primeira frase. Nesta seção, procuramos mostrar algumas estratégias linguístico-discursivas da instauração desta tensão como base do conto em questão. Alguns conceitos de semiótica geral ou semiótica tensiva serão convocados aqui e ali, a partir da necessidade de explicitação de pontos específicos da análise.

Iniciamos pela observação das estruturas narrativas subjacentes. Inspirada no modelo narrativo de Propp (1984 [1928]), a semiótica francesa postula que a todo texto subjaz uma estrutura narrativa, chamada, nesta disciplina, de "esquema narrativo canônico". A este esquema se relacionam os percursos de "sujeitos" em busca 
da conjunção ou da disjunção com certos objetos de valor (grosso modo, objetivos, aquilo que o sujeito quer). Em "O barril de Amontillado" se tomamos o ponto de vista de Fortunato, seu objeto é a degustação do Amontillado, com o que pode reforçar ao amigo a sua posição de excepcional conhecedor de vinhos. De outro lado, se tomamos a posição de Montresor, o que ele busca, o seu objeto é a vingança, como forma de reparação de seu orgulho ferido.

Esse "esquema narrativo" proposto pela semiótica é organizado em quatro etapas principais, que, mesmo quando não explícitas nos textos, são pressupostas. Essas etapas são:

1. manipulação: etapa em que um sujeito (S1) tenta convencer outro (S2) a fazer algo ou a acreditar em algo (em termos modais, dizemos que S1 "faz-fazer" ou “faz-crer", o que pode ser desdobrado em "faz-querer" e/ou “faz-dever").

2. competencialização: etapa em que S2, agora já querendo ou devendo fazer algo (em outras palavras, mais técnicas, já modalizado pelo querer e/ou pelo dever), se prepara para executar uma ação.

3. ação: etapa em que S2, agora já preparado e competente (ele sabe e pode fazer; já está modalizado pelo saber e pelo poder), age de modo a atingir seu objetivo.

4. julgamento: em que S1 avalia uma ação realizada por S2 e lhe sanciona positiva ou negativamente, oferecendo-lhe um prêmio ou uma punição.

Notemos que essa estrutura pode ser observada nos mais diversos tipos de textos e práticas sociais. Se tomamos a prática da "aula" como um texto, temos que o professor ocupa a posição de um sujeito que tenta conversar outros sujeitos (os alunos) a fazer algo ou acreditar em algo (fazer as tarefas, estudar ou "acreditar" no conteúdo das aulas); munido do saber (competente, "modalizado"), o aluno realiza uma tarefa (por exemplo, uma prova ou um trabalho) e tem esse seu fazer avaliado pelo professor que o "premia" com uma nota, em caso de sanção positiva, ou o "pune" com a reprovação, em caso de sanção negativa ${ }^{10}$.

10 De maneira ainda mais óbvia, podemos encontrar essas estruturas nos textos narrativos, sejam eles escritos ou audiovisuais. Por exemplo, em Doutor Sono, de Stephen King (2014 [2013]), sequência do já clássico O Iluminado (2017 [1977]), Dan Torrance (“Danny”), atormentado pelo passado e 
Como já mencionamos, nem sempre essas etapas estão explícitas no texto. É comum que apenas uma ou outra parte do percurso de um sujeito seja apresentada. Quando ocorre a supressão de uma ou mais dessas etapas, a narrativa é acelerada. Como vimos, segundo a semiótica tensiva, quebras de expectativas e acelerações de conteúdos podem fazer aflorar a tensão. Em "O barril de Amontillado" temos um início abrupto, um texto que já começa "em movimento", no sentido de que ele se inicia já com o narrador - Montresor — na posição de um "julgador" que avalia um fazer (o de Fortunato) que nem ao menos nos foi dado a conhecer por completo: sabemos apenas que Montresor foi insultado por Fortunato, sendo essa ofensa o ápice de uma série de injúrias. No entanto, não sabemos quais exatamente foram os insultos, nem em que condições foram proferidos. A primeira frase do conto é "Suportei da melhor forma que pude as muitas injúrias de Fortunato, mas quando ele se atreveu a insultar-me, jurei vingança" (POE, 2017 [1846], p. 145). A não explicitação das outras etapas — pressupostas — do esquema narrativo é uma primeira estratégia que instaura no conto, já de saída, uma espécie de "embrião" da tensão, que pode ser sentida pelo leitor, que diz para si mesmo "espera, o que está acontecendo aqui?". Tal sensação é muito diferente daquela do leitor que teria diante de si a explicação detalhada de tudo que teria acontecido. A tensão deste primeiro pequeno impacto ainda não está relacionada a um efeito de terror/ horror, mas ajuda a estabelecer uma tensão "de base" neste texto.

por não conseguir conviver em paz com seu dom (sua "iluminação"), passa a querer e dever salvar a menina também iluminada Abra Stone, quando ela lhe conta, telepaticamente, sobre a ameaça do Verdadeiro Nó, grupo de paranormais que se sustentam "sugando" a iluminação de crianças e matando-as no processo (para usar a terminologia da semiótica, Daniel foi “manipulado” por Abra). Para tanto, ele precisa destruir o Nó (sua ação). Ele possui parte da competência necessária para a tarefa e adquire ao longo da narrativa o restante desta competência, figurativizada pela ajuda telepática que recebe de Abra, pelo auxílio de seu amigo Billy Freeman, pelo “vapor" que coleta da avó de Abra, Concetta, no momento de sua morte ("arma" que lhe permitirá destruir os últimos membros do Nó), e, ainda, pela ajuda do espírito de seu pai, Jack Torrance, que o auxilia a matar Rose, a líder do Nó, ao empurrá-la de uma plataforma de observação. A fase da sanção é apresentada no epílogo, que mostra Dan 15 anos depois, feliz por ter salvado Abra (que, descobriu no meio da narrativa, era sua sobrinha), sóbrio (era alcoólatra no começo) e em paz com o seu dom, que emprega para ajudar pessoas à beira da morte (recompensado positivamente com uma vida feliz). 
A partir daí, vamos acompanhar a vingança de Montresor, a punição que ele quer aplicar em Fortunato, conforme ela se desenrola. Na verdade, logo de início sabemos que tal punição de fato ocorreu, mas apenas pouco a pouco vamos tendo acesso ao que aconteceu. Vale acrescentar que a vingança é contada em primeira pessoa por Fortunato, de um modo tão intimista e subjetivo que se suscita um efeito de sentido de presentificação das cenas. Tendo sido insultado pelo amigo, Montresor tem o orgulho ferido e é propriamente este orgulho que funciona aqui como "gatilho", como instigador da vingança que Montresor planejou (o orgulho e a consequente vingança, enraizados até mesmo na legenda do brasão de sua família: Nemo me impune lacessit: "Ninguém me fere impunemente").

Daqui por diante, em se tratando da execução de seu plano, não há a supressão das etapas do esquema narrativo do ponto de vista do fazer de Montresor, mas continua, como elemento importante para a manutenção da tensão, o jogo entre o saber e o não saber, por parte de Fortunato e por parte do enunciatário; um jogo entre o que é ou não revelado. Montresor engana Fortunato, que o segue para a sua casa, totalmente "no escuro", desconhecedor do que está por vir. Contudo, o fato de Montresor regular o conhecimento de Fortunato só gera suspense e tensão porque há um outro jogo acontecendo, entre o enunciado e a enunciação simulados dentro do conto. Em tal simulação, temos, no plano da enunciação (uma enunciação "simulada" dentro do enunciado), Montresor enquanto narrador, contando o ocorrido a certos narratários: "Os senhores, que conhecem tão bem a natureza de minha alma..." (p. 145); no plano do enunciado, temos a história contada, o sujeito Montresor atraindo Fortunato até a sua casa e executando o plano sinistro, sem que Fortunato saiba o que lhe aguarda. Os narratários têm muito mais acesso ao que irá acontecer do que Fortunato jamais teve. Logo na primeira página, já sabem que a ideia de matar Fortunato assomou Montresor ("Continuei a sorrir-lhe, e ele não percebeu que, agora, eu sorria à ideia de matá-lo", p. 145).

Fora dessa simulação do enunciado, temos, obviamente, um enunciador-autor ${ }^{11}$

11 A semiótica difere enunciador e enunciatário de autor e leitor, mas aqui usaremos os termos intercambiavelmente, ignorando suas nuances, a fim de melhor comunicar o que pretendemos para leitores não afeitos à teoria. Para um entendimento sobre as diferenças mencionadas, ver Fiorin (2005). 
que produz um enunciado (o conto como um todo) com vistas a atingir um enunciatário-leitor. Também aqui se coloca a questão do saber e do fazer-saber. Nós, enunciatários-leitores, assim como os narratários inscritos no texto, também passamos a conhecer muito mais acerca dos acontecimentos do que Fortunato e, juntamente com os narratários, vamos recebendo pouco a pouco os detalhes da história; assim como os narratários, nós sabemos que Fortunato não sabe o que lhe aguarda e ficamos, de certa maneira, angustiados aos nos imaginarmos em seu lugar.

Pode-se dizer, então, que é no descompasso entre esses saberes (narratários e enunciatários sabem muito mais do que Fortunato) que se estabelece o suspense. Instaura-se uma tensão, na medida em que os narratários e enunciatários passam a esperar, a antecipar o momento em que Fortunato se dará conta daquilo que eles já sabem (mas não sabem exatamente como se dará ou em que momento da história), ou seja, da armadilha que levaria à sua morte. É o mesmo mecanismo do célebre exemplo da bomba em cena, dado por Hitchcock $(1970)^{12}$. O cineasta teoriza sobre o suspense falando sobre duas possibilidades para uma cena. Na primeira, pessoas estariam à mesa, conversando banalidades quando, de repente, uma bomba explode; o impacto é alto, a audiência tem um choque, mas o efeito disso é pouco duradouro. Na segunda possibilidade, na mesma cena, a audiência ficaria sabendo logo no início que há uma bomba prestes a explodir e passa a esperar a explosão; a tensão se alonga no tempo, a curiosidade do espectador é aguçada. A bomba explodirá ou não? Se for desarmada, como acontecerá? Essa segunda possibilidade engaja mais o enunciário; nas palavras de Hitchcock, "you've got the audience working”.

Existe, então, uma linha de base de tensão dentro do enunciado, que acompanha a espera dos narratários, e outra que extrapola o texto e se instaura na situação enunciativa, já que acomete o enunciatário-leitor (doravante, apenas leitor) que sabe ainda um pouco menos que os narratários. O leitor não sabe, por exemplo, quem são esses narratários ("os senhores") a quem Montresor se dirige, nem em que situação se dá a “confissão” de Montresor (estaria ele se confessando a um padre? A amigos? À Polícia?).

12 Vídeo da fala do Hitchcock no Seminário do American Filme Institute, em 1970, disponível em <https://youtu.be/DPFsuc_M_3E>, acesso em 08 de novembro de 2021. 
Embora o fazer-saber aos narratários e leitores se dê de modo paulatino, não acelerado (o que poderia ir contra o que explicamos anteriormente sobre aceleração dos conteúdos), o que determina a tensão aqui é o desalinho entre os saberes nos diferentes níveis. Pensando em termos de implicação e concessão, de esperados e inesperados, a situação menos tônica seria aquela em que a cada nível (personageml — personagem2; narrador - narratários; enunciador - leitores) se revelassem ou se escondessem fatos na mesma medida. Se não é isso o que ocorre, essa descontinuidade entre os níveis mantém a tensão, o suspense. Em “O barril de Amontillado”, o descompasso entre o que se sabe ou se dá a saber nos diferentes níveis enunciativos sustenta, mantém até o fim do texto a tensão criada no primeiro parágrafo.

Sobre esta base já tensa, assentam-se momentos de assomo e resolução, num "sobe e desce" tensivo que se assemelha à linha melódica da fala, mas agora atuando no plano do conteúdo e não no da expressão. Na próxima seção, abordaremos esses momentos de assomo.

\section{EXACERBAÇÃO DA TENSÃO}

Segundo Mancini (2020, p. 30), “em suma, tudo aquilo que se apresenta subitamente, provando estranheza, comoção, surpresa, susto, enquanto quebra de expectativa, cria acentos". Segundo Tatit (2019, p. 149), em sua acepção semiótica, o acento “constitui sempre um caso de alta intensidade e pouca extensidade". Para empregar o exemplo já lançado neste artigo, entre "O gato subiu no telhado; o gato caiu, o gato morreu" e "O gato morreu", a última opção é a acentuada, pois é forte, sendo a tonicidade dada por um tema que causa comoção e, ao mesmo tempo, é algo que ocorre de modo concentrado no tempo (pouca extensidade).

Sobre a base tensa que delineamos e procuramos explicar através da observação de algumas estratégias linguístico-discursivas na seção anterior, recaem, ainda, em "O barril de Amontillado", diversos acentos, que criam exacerbações da tensão. Tatit (2019, citando ZILBERBERG, 2012) fala em “incrementos" do acento, uma vez que já se está partindo de uma base tônica. Nesta seção, tratamos deste recrudescimento 
(que, na semiótica tensiva, é comum aparecer simbolizado por “++” (ou "mais mais”, isto é, a intensificação do que já era intenso).

O primeiro momento de recrudescimento no conto em questão se dá na passagem em que o narrador revela a ideia de matar Fortunato: "Fique entendido que jamais dei oportunidade a Fortunato, quer por palavras, que por atos, de duvidar de minha boa disposição. Continuei a sorrir-lhe como antes, e ele não percebeu que, agora, eu sorria à ideia de matá-lo" (p. 145). Existe acento aqui por pelo menos dois motivos: a) pela revelação, súbita e tão antecipadamente no texto de que a vingança culminará num assassinato (tema que costuma ser tônico por gerar comoção); e b) pela ironia ${ }^{13}$ relatada pelo narrador que sorria a Fortunato um sorriso que aparentava boa disposição e gentileza, mas que significava gozo pela proximidade da concretização da vingança. Ainda sobre essa passagem, podemos pensar na figurativização ${ }^{14}$ do tema da vingança enquanto assassinato. Por mais que a vingança já seja esperada — já que revelada logo na primeira linha - ela ser um assassinato é inesperado, já que desproporcional ao que a ensejou: uma série de insultos que, por pior que sejam, não deveriam, a princípio suscitar tão grande punição.

Outro acento se percebe no momento em que o narrador conta que o plano macabro foi executado no carnaval. Aqui, cabe um comentário acerca de outro nível no modelo analítico da semiótica, o nível discursivo, que é aquele em que as estruturas narrativas subjacentes (que vimos brevemente na subseção anterior) são revestidas por temas e figuras que lhe dão concretude. É aqui, também, que está em jogo a colocação de pessoas, tempos e espaços no discurso/texto. Ao figurativizar tempo e espaço enquanto "estação carnavalesca”, o enunciador põe em circulação o tema da vida, oposto ao da morte. O contraste entre morte e vida, passível de provocar desconcerto no leitor, é ainda realçado pela descrição das vestes de Fortunato. Vejamos o trecho: "Fantasiara-se de palhaço. Trazia um traje muito justo, de listas, e a cabeça coberta por um chapéu cônico, cheio de guizos" (p. 146).

O próximo momento de uma subida no percurso tensivo do conto (ou "arco

13 Em análise deste conto, Terra (2017) também aborda este ponto.

14 “Figurativização" é entendido como concretização ou enriquecimento semântico. 
tensivo" ${ }^{15}$, nos termos de Mancini, 2020) também se dá em termos de figurativização, desta vez, do espaço. Ocorre quando Montresor começa a guiar Fortunato já dentro de sua casa, por um caminho escuro (precisam de tochas) e sombrio. A descrição deste espaço remete à morte e é passível de causar no leitor os “arrepios", os "calafrios" esperados em histórias de horror. As seguintes passagens compõem este percurso figurativo: "tirando duas tochas (...), guiei-o", “adega subterrânea”, "longa e sinuosa escada”, “chão úmido das catacumbas” (p. 147, 148).

O espaço figurativizado como sombrio e macabro ainda vai aparecer mais adiante, em outros momentos do conto, conforme eles vão avançando pelo subsolo, como em "paredes com esqueletos empilhados", “musgo das paredes", “cripta profunda, cujo ar confinado enfraquecia a chama de nossas tochas", "gotas de humidade", "pilha de despojos humanos", "ossos derrubados no chão", "tocha de luz mortiça” (p. 149-151). Outra figura espacial que ajuda a compor a tensão é uma escada em caracol que Monstresor e Fortunato descem; para Borges-Filho (2009, p. 9): "O tema sob essas figuras parece evidente: o fato de Fortunato se enredar cada vez mais na trama traçada por Montresor”. A forma deste tipo de escada e a associação proposta por Borges-Filho nos faz pensar em algum tipo de concentração espacial (portanto, "pouca" extensidade). Fosse a figura outra, uma figura que representasse uma difusão espacial, perderíamos a ideia de enredarmo-nos na trama e a tensão suscitada talvez fosse menor.

Falamos na primeira parte sobre a tensão que emerge do descompasso entre saberes revelados a Fortunato, narratários e leitores, e que isso perpassa o texto e ajuda a criar a sua base tônica. Pensando de maneira mais pontual, podemos identificar passagens em que existe ainda um incremento acentual dado pela forma como Montresor ludibria Fortunato ${ }^{16}$, fingindo se preocupar com a sua saúde. Ele parece ser preocupado, mas não é; e está imbuído do desejo de vingança, mas não parece estar.

15 Preferimos empregar "percurso" em vez de "arco" porque o segundo nos remete à ideia de algo que sobe e desce (uma curva) e num "percurso” não há necessariamente este movimento.

16 Terra (2017) também analisa essa questão. 
A mentira (parecer + não-ser) e o segredo (ser + não-parecer) ${ }^{17}$ são concessivos, são da ordem do "apesar de X, Y" e daí o aumento em tonicidade. Acrescentamos que, neste caso específico, não é apenas uma questão de concessividade, mas, ainda, de um grau $^{18}$ elevado de concessividade, construído a partir da insistência, das repetições na fala de Montresor, que adensam em Fortunato a ideia de que "está tudo bem", quando não está. Acrescente-se a isso a ironia que atravessa a fala de Montresor, beirando o sadismo. Vejamos dois trechos relevantes para o que acabamos de expor (com destaques nossos):

— Venha - acrescentei com decisão - vamos voltar, sua saúde é preciosa. Você é rico, respeitado, admirado, amado, é feliz, como um dia eu também o fui. Sua falta será sentida (...). Vamos voltar; você ficará doente e eu não quero responsabilizar-me por isso (...). - Chega - redarguiu ele. - A tosse não tem importância, não me matará. Não morrerei de uma simples tosse.

- Claro, claro - respondi, e na verdade não tive intenção de alarmá-lo desnecessariamente (...) (POE, 2017, p. 148).

- Beba - disse, oferecendo-lhe o vinho.

(...).

- Bebo - disse ele - aos mortos que repousam à nossa volta.

- E eu, à sua longa vida (POE, 2017, p. 149).

O próximo acréscimo acentual se dá quando finalmente Fortunato se percebe numa armadilha: "encontrando seu avanço obstado por uma rocha, parou, estupidamente surpreso" (p. 151, destaques nossos). Mais uma vez, concessão: apesar de tudo parecer correr bem, vem o golpe. E, ainda, vem subitamente. É o que se pode chamar de “acontecimento". Na semiótica tensiva, "acontecimento" é aquilo que irrompe no percurso de um sujeito, o que lhe causa surpresa. O acontecimento suprime a dura-

17 “Ser" e "parecer" são chamadas, pela semiótica, de "modalidades veridictórias". A depender de como são articuladas logicamente, geram a mentira ou o segredo, a falsidade ou a verdade (GREIMAS \& COURTÉS, 1979).

18 A ideia de graus de implicação ou concessividade, aliados às modalidades veridictórias do ser e do parecer foram aparecem em Lisboa (2016). 
ção, porque é extremamente acelerado e, por isso, impactante. Notemos, ainda, que Fortunato é descrito como atônito por Montresor: "Enrolados os grilhões ao redor de seu pulso, foi coisa de poucos segundos algemá-lo. Ele estava atônito demais para resistir" (p. 152). Este estado de Fortunato vai ao encontro do que afirma Zilberberg sobre o agir e o sentir do sujeito, nesses casos: "o acontecimento arrebata para si todo o agir, não deixando nada além de suportar" (2006a, p. 198).

Notemos que o acontecimento se dá no nível do enunciado (é uma passagem abrupta de uma atonia ou quase atonia para uma saturação ou tonicidade máxima). No nível da enunciação, o impacto é menor porque o leitor já espera desde o início do conto por alguma coisa que acontecerá com Fortunato (nesse nível, se acompanham os incrementos acentuais, pouco a pouco); é menor, mas não inexistente, porque a tensão do leitor se dá pelo fato de que ele, leitor, não sabe em que momento haverá essa "virada" e, assim, quando ela sobrevém, não deixa de haver certo impacto.

A partir deste ponto, diminui um pouco o descompasso entre o que Fortunato sabe e o que o leitor sabe. Por um lado, Fortunato vê-se preso e provavelmente intui que algo horrível sucederá àquela armadilha, mas não tem certeza ainda do quê; enquanto o leitor também sabe como Fortunato foi preso, sabe que ele morrerá, mas ainda não sabe como. De outro lado, Fortunato e o leitor vão descobrir simultaneamente qual é o destino exato, terrível, do primeiro. E é esse destino horrível, revelado apenas agora que causa mais um aumento de tonicidade.

Esse incremento vem, desta vez, não sobre a base, mas sobre os picos que já vinham ocorrendo. Em outras palavras, ao recrudescimento que vimos apontando até agora, soma-se um novo "mais", mais um acento, completando-se o percurso numa direção tensiva de ascendência, chegando-se a um estado de saturação (Cf. TATIT, 2019 , p. 109; 229). Isso ocorre no momento em que se vislumbra que a morte - por si só um castigo exagerado em comparação ao delito de Fortunato - será uma morte horrível: um emparedamento. Vejamos esta passagem no conto: “(...) pus-me em atividade por entre a pilha de ossos de que já falei. Atirando-os para o lado, deixei a descoberto certa quantidade de pedras para construção e argamassa. (...), comecei a emparedar com vigor a entrada no nicho" (p. 152). O que antes pensávamos ser um assassinato pontual, agora sabemos ser durativo. Esse "morrer aos poucos" é acom- 
panhado de grande sofrimento, causando mais comoção. Ao escolher figurativizar a vingança de Montresor com uma morte, o enunciador confere tonicidade ao texto; ao escolher figurativizar esta morte com uma morte lenta e sofrida, causa ainda mais comoção e mais tensão.

O "susto" causado pela ciência do emparedamento passa a ser atenuado logo em seguida, desdobrado temporalmente na extensidade, enquanto se acompanha o fazer de Montresor, tijolo a tijolo. Apesar deste rearranjo cognitivo - isto é, passada a arrebatação, Fortunato, os narratários e os leitores já compreendem o que se passa —, outra "onda" de tonicidade sobrevém e a estratégia discursiva empregada para esse novo incremento de acento é o apelo sinestésico por meio dos sons. Montresor não vê, mas ouve "o agitar furioso da corrente" e, assim, o leitor, com ele tem uma imagem do desespero de Fortunato. Neste ponto espera-se que os ruídos abalem Montresor de algum modo, mas, ao contrário, ele informa que "O ruído prolongou-se por vários minutos durante os quais, para ouvi-lo com maior satisfação, interrompi o trabalho e sentei-me sobre os ossos" (p. 152).

Ainda sobre a sonoridade e o desespero de Fortunato, a descrição de seus gritos ("grito surdo e lamentoso", "sucessão de gritos altos e agudos", p. 152, 153) contribui para manter elevada a tensão no conto, que aumenta ainda mais quando, após um breve momento de hesitação, Montresor, numa atitude impiedosa, faz eco, arremeda os gritos de Fortunato: "Respondi aos gritos do que clamava. Fiz-lhes eco, ajudei-os, ultrapassei-os em volume e intensidade" (p. 153).

Incrédulo sobre o que se passa, Fortunato começa a rir e "compreende" tudo como uma brincadeira de Montresor (sua tentativa de conceber o que ocorre, já que inacreditável). Neste ponto, mantém-se a estratégia do descompasso entre o que sabe Fortunato (ainda acredita ser uma brincadeira) e o que sabem os narratários e o leitor (não há brincadeira nenhuma ali).

Mais uma subida acentual se verifica na súplica de Fortunato, ao perceber que Montresor realmente o largaria lá: “ - Pelo amor de Deus, Montresor!” (p. 154). Nesta breve passagem, amontoam-se estratégias discursivas que culminam em alta tonicidade: o próprio conteúdo semântico da súplica; a comoção causada pelo fato de se dar a saber aqui que, de fato, Fortunato finalmente entendeu seu destino; o fato de 
esta súplica não ser contada, mas mostrada pelo narrador, isto é, colocada "na boca da personagem" pelo discurso direto (criação de um efeito de sentido de realidade) ${ }^{19}$; por fim, da ordem do plano da expressão, o destaque gráfico que é dado ao texto ${ }^{20}$.

O conto, então, encaminha-se para o fim, ainda tônico, pois em nenhum momento Montresor se importa com o sofrimento iminente de Fortunato; ao contrário, quando diz estar nauseado, reforça, sarcasticamente, que só o está pela umidade das catacumbas. Neste último parágrafo, aparece mais uma vez a figura dos guizos na fantasia de Fortunato, evocados sonoramente, numa repetição do contraponto já colocado anteriormente entre o "alegre" e "sombrio" (que, pode-se dizer, representam, mais profundamente, a oposição entre "vida" e "morte").

$\mathrm{Na}$ antepenúltima frase, é finalmente revelado que a história se deu 50 anos atrás. Aqui podemos pensar em nova surpresa, dos narratários e dos leitores, pois não seria de se esperar que tal crime ficasse tanto tempo sem resolução. Na frase final, em latim - In pace requiescat!"21 (p. 154) - o conto fecha com mais sarcasmo de Montresor, com um certo cinismo, exacerbado pelo ponto de exclamação e que funciona para fechar a história sem baixar o seu nível de tensão. Nenhum alívio se estabelece, nem para Fortunato, nem para os narratários, nem para o leitor.

\section{CONSIDERAÇÕES FINAIS}

Como dissemos na Introdução, o que ocorre em "O barril de Amontillado" não é uma transição de um estado de total relaxamento para momentos de tensão, mas sim o estabelecimento, "de saída", de uma base tensa, a partir da qual emergem momentos ainda mais tensos. Tais momentos são criados por diversas estratégias

19 Fiorin (2005, p. 74) afirma que "O discurso direto, em geral, cria um efeito de sentido de realidade, pois dá a impressão de que o narrador está apenas repetindo o que disse o interlocutor".

20 Na edição que empregamos (POE, 2017) e também na versão em língua inglesa disponível em <https://www.ibiblio.org/ebooks/Poe/Amontillado.pdf>, o destaque é dado pelo emprego de itálico.

21 Em português, “Descanse em paz!”. 
linguístico-discursivas, que apontamos ao longo do artigo. Esses "acentos" ou "picos de tensão" geralmente se criam a partir de tudo aquilo que é inesperado, concessivo; e, se ocorrerem também de forma concentrada no tempo ou no espaço, são, além de tensos, impactantes; e mais impactantes quanto mais concentrados, como é o caso do chamado "acontecimento" que arrebata o sujeito.

Mostramos que há um percurso tensivo ao longo do texto e que este se verifica globalmente, mas a partir de estratégias que ocorrem em diferentes níveis e através de distintas "questões" textuais e discursivas (quanto à narratividade; quanto à articulação de modalidades como o saber e o não saber, ou o ser e o parecer; quanto aos temas e figuras empregados; quanto às estratégias de colocação de pessoas, tempos, espaços em cena; quanto à cessão ou não de vozes aos personagens, etc.). Há de se considerar também o que se passa no nível do enunciado e no nível da enunciação. O nível da enunciação e as reações esperadas nos enunciatários-leitores nos parecem de fundamental importância em se tratando da literatura de horror, se nos apegamos à ideia de horror como definida por Carroll (1990), que citamos na introdução.

Essa ideia do efeito - ou sentimento - que o texto de horror causa no enunciatário pode ser aliada à ideia de próprio texto enquanto "acontecimento". Sendo o enunciatário um sujeito, o texto de horror, tônico por natureza, é um acontecimento que causa sua arrebatação. No acontecimento, como vimos, o sujeito já não age, apenas "sofre" (sente). Se o próprio objeto - no caso, o próprio texto - é um acontecimento em relação ao sujeito enunciatário, este se passiviza e aquele se ativa, havendo, pois, estetização ou "emoção estética" (Zilberberg, p. 145). A isso podemos relacionar a ideia de "horror artístico" de Carroll (1990) e o horror enquanto "efeito estético" mencionado por Nestarez (2019). A estetização do horror é possibilitada pelos mecanismos de tensão no interior do enunciado e também, talvez sobretudo, naquilo que se passa no texto com relação ao enunciatário, pois depois da instauração do suspense, não há uma resolução em termos de "alívio"; ao contrário, o conto termina num ápice. $\mathrm{O}$ assassinato horrível, com toques de sadismo, de fato se concretiza; não há nada que salve Fortunato (ou que traga os enunciatários de volta para um estado relaxado).

Em romances de horror, a tensão não se sustenta da mesma maneira que nos contos; ela tende a se manter mais baixa (embora também haja picos aqui e ali), até 
mesmo por conta da extensão das obras, pois seria difícil sustentar a tonicidade por muito tempo, inclusive do ponto de vista da cognição do leitor. A brevidade do conto favorece o impacto (o que vai ao encontro das postulações da semiótica tensiva), como bem observou o próprio Poe, para quem, no conto ou no poema, uma longa extensão diluiria o efeito desejado (POE, 1984 e 2019).

Parece-nos, a partir de diversos outros textos de horror que nos vêm à memória, que um perfil tensivo tal como o que delineamos durante a análise de "O barril de Amontillado" pode também ser encontrado em outros contos do gênero, ou seja, tensões que se assentam sobre bases já tensas e uma direção ascendente em que vão ocorrendo incrementos de acentos, frequentemente terminando "lá em cima", no ápice. Contudo, apenas análises empíricas futuras podem confirmar essa hipótese. Caso venha a se confirmar, talvez estejamos diante de uma característica estrutural, se não definidora, ao menos frequente, dos "contos de horror", para além da definição geral do horror oferecida, por exemplo, por Carroll, que é centrada no efeito provocado no enunciatário.

Trabalhos futuros que podem complementar o que iniciamos com essa análise incluem o exame de outros contos de horror, tanto de Poe quanto de outros autores, a fim de verificar se o esquema de tensões empregado e os modos de gerar a tensão são os mesmos dentro deste autor - o que poderia apontar para um estilo individual —, ou em autores diferentes. Além disso, caberiam ainda reflexões que tentassem responder a seguinte pergunta: de que modo estariam os picos de tensão do conto relacionados necessariamente à provocação do horror? Esperamos que este trabalho possa trazer alguma clareza quanto à construção da tensão em contos de horror. 


\section{REFERÊNCIAS}

ALMEIDA, D. Semiótica Francesa: panorama e possibilidades na Linguística Aplicada. In: Linguística Aplicada na Unicamp: travessias e perspectivas. Bauru: Canal 6, 2021.

BERTRAND, D. Caminhos da semiótica literária. Bauru: Edusc, 2003.

BARROS, D. L. P. Teoria semiótica do texto. São Paulo: Ática, 2003a.

BARROS, D. L. P. Estudos do discurso. In: Fiorin, J. L. (org). Introdução à Linguística, vol. II: princípios de análise. 2a. ed. São Paulo: Contexto, 2003b.

BORGES-FILHO, O. Uma leitura semiótica do espaço: O barril de Amontillado. CASA: Cadernos de semiótica aplicada, vol.7 n.1, 2009, p. 1-15.

CARROLL, N. The philosophy of horror or paradoxes of heart. New York: Routledge, 1990. FIORIN, J. As astúcias da enunciação. São Paulo: Ática, 2005.

GREIMAS, A. J. Sémantique structurale: recherche de méthode. Paris: Larousse, 1966.

GREIMAS, A. J. Du sens. Essais de sémiotiques. Paris: Du Seuil, 1970.

GREIMAS, A. J. ; COURTÉS, J. Sémiotique: dictionnaire raisonné de la théorie du langage. Paris: Hachette, 1979.

HITCHCOCK, A. Palestra proferida em um Seminário do American Film Institute. 1970. Disponível em: < https://youtu.be/DPFsuc_M_3E > Acesso em: $08 \mathrm{de}$ nov. 2021.

HJELMSLEV, L. Prolegômenos a uma teoria da linguagem. São Paulo: Perspectiva, 2005.

KING, S. O Iluminado. São Paulo: Suma, 2017.

KING, S. Doutor Sono. São Paulo: Suma, 2014.

LISBOA, V. Efeitos sensíveis na percepção das veridicções: uma leitura tensiva das modalidades veridictórias a partir da análise semiótica da HQ Watchmen. Dissertação (Programa de Pós-graduação em Estudos de Linguagem) - Universidade Federal Fluminense, 2016.

MANCINI, R. A tradução enquanto processo. Cadernos de Tradução, Florianópolis, v. 40, n. 3,2020 , p. $14-33$.

NESTAREZ, O. Edgar Allan Poe: o mestre que foi o arquiteto do horror. Terra Treva. 26 de nov. de 2019. Disponível em: <https://www.terratreva.com/post/escre- 
va-seu-blog-pelo-desktop-e-pelo-mobile> Acesso em: 21 abr. 2021.

POE, E. A. (1946). The cask of Amontillado. Disponível em: < https://www.ibiblio.org/ ebooks/Poe/Amontillado.pdf> Acesso em: 10 abr. 2021.

POE, E. A. Edgar Allan Poe: essays and reviews. New York: Library of America, 1984.

POE, E. A. O barril de Amontillado. Histórias extraordinárias. Tradução de José Paulo Paes. São Paulo: Companhia das Letras, 2017, p.143-154.

POE, E. A. A filosofia da composição. O Corvo. Tradução de Paulo Henriques Britto. São Paulo: Cia das Letras, 2019, p. 57-74.

PROPP, V. Morfologia do conto maravilhoso. Rio de Janeiro: Forense Universitária, 1984. SAUSSURE, F. Curso de Lingüistica Geral. São Paulo: Cultrix, 2002.

TATIT, L. Análise semiótica através das letras. São Paulo: Ateliê Editorial. 2001.

TATIT, L. Passos da semiótica tensiva. Cotia, SP: Ateliê. 2019.

TERRA, E. O acontecimento e o mal em “O barril de Amontillado”, de Edgar Allan Poe. Acta Semiótica et Lingvistica, v. 21, 2017, p. 2-13.

ZILBERBERG, C. Síntese da gramática tensiva. Revista Significação. Eca. USP, n. 25, 2006a.

ZILBERBERG, C. Razão e poética do sentido. São Paulo: Edusp, 2006b

ZILBERBERG, C. La structure tensive. Liège: Presses universitaires de Liège, 2012. 